\title{
Methodology Report \\ Total 25-Hydroxyvitamin D Determination by an Entry Level Triple Quadrupole Instrument: Comparison between Two Commercial Kits
}

\author{
Jacopo Gervasoni, Andrea Cocci, Cecilia Zuppi, and Silvia Persichilli \\ Istituto di Biochimica e Biochimica Clinica, Università Cattolica del Sacro Cuore, Largo A. Gemelli 8, 00168 Rome, Italy \\ Correspondence should be addressed to Silvia Persichilli; spersichilli@rm.unicatt.it
}

Received 29 November 2012; Revised 18 January 2013; Accepted 25 January 2013

Academic Editor: Antonio La Gioia

Copyright (C) 2013 Jacopo Gervasoni et al. This is an open access article distributed under the Creative Commons Attribution License, which permits unrestricted use, distribution, and reproduction in any medium, provided the original work is properly cited.

\begin{abstract}
Objective. 25-hydroxyvitamin $\mathrm{D}_{2} / \mathrm{D}_{3}\left(25-\mathrm{OHD}_{2} / \mathrm{D}_{3}\right)$ determination is a reliable biomarker for vitamin $\mathrm{D}$ status. Liquid chromatography-tandem mass spectrometry was recently proposed as a reference method for vitamin $\mathrm{D}$ status evaluation. The aim of this work is to compare two commercial kits (Chromsystems and PerkinElmer) for $25-\mathrm{OHD}_{2} / \mathrm{D}_{3}$ determination by our entry level LC-MS/MS. Design and Methods. Chromsystems kit adds an online trap column to an HPLC column and provides atmospheric pressure chemical ionization, isotopically labeled internal standard, and 4 calibrator points. PerkinElmer kit uses a solvent extraction and protein precipitation method. This kit can be used with or without derivatization with, respectively, electrospray and atmospheric pressure chemical ionization. For each analyte, there are isotopically labeled internal standards and 7 deuterated calibrator points. Results. Performance characteristics are acceptable for both methods. Mean bias between methods calculated on 70 samples was $1.9 \mathrm{ng} / \mathrm{mL}$. Linear regression analysis gave an $R^{2}$ of $0.94 .25-\mathrm{OHD}_{2}$ is detectable only with PerkinElmer kit in derivatized assay option. Conclusion. Both methods are suitable for routine. Chromsystems kit minimizes manual sample preparation, requiring only protein precipitation, but, with our system, $25-\mathrm{OHD}_{2}$ is not detectable. PerkinElmer kit without derivatization does not guarantee acceptable performance with our LC-MS/MS system, as sample is not purified online. Derivatization provides sufficient sensitivity for $25-\mathrm{OHD}_{2}$ detection.
\end{abstract}

\section{Introduction}

Vitamin D (vitD) is is critical for the regulation of calcium and phosphate homeostasis and is implicated in important biological processes [1]. VitD exists in two forms; vit $\mathrm{D}_{3}$ (cholecalciferol) is formed in the skin upon exposure to sunlight; vitD $\mathrm{D}_{2}$ (ergocalciferol) is obtained from the ultraviolet irradiation of plants materials. These two vitD forms are metabolized in the liver to give 25-hydroxy vitamin D (25-OHD), further hydrolyzed in the kidney to biologically active metabolite 1,25-dihydroxy vitamin $\mathrm{D}$ (1,25-OHD). This last metabolite is difficult to measure, because it is present at extremely low concentrations $(15-60 \mathrm{pg} / \mathrm{mL}$ ), thus, circulating liver metabolites $25-\mathrm{OHD}_{2} / \mathrm{D}_{3}$ are recognized as markers for vitamin $\mathrm{D}$ status $[2,3]$.

Recently vitD status has been associated with several diseases including cancer cardiovascular disease, diabetes, multiple sclerosis, osteoporosis, rheumatoid arthritis, and chronic pain [4].

Methods for $25-\mathrm{OHD}_{3}$ and $25-\mathrm{OHD}_{2}$ determination can be grouped in immunochemical methods (based on radioactive, enzymatic, or chemiluminescence detection) and chromatographic methods (HPLC and LC-MS/MS).

Immunoassay methods are the most used for their rapidity, despite that several studies reported problems of reproducibility and interferences. Recent papers have reviewed performance and limitations of immunochemical, HPLCbased, and liquid chromatography-tandem mass spectrometry (LC-MS/MS) methods $[5,6]$. One limitation in the 25$\mathrm{OHD}_{2} / \mathrm{D}_{3}$ measurement was represented by the lack of reference standards until the development of two ethanol-based calibrators (SRM 2972) and four serum-based calibrators (SRM 972) by the US National Institute of Standards and Technology (NIST). There are two LC-MS/MS methods as 
reference methods by the Joint Committee for Traceability in Laboratory Medicine [7, 8].

The release of these standards significantly contributed to increasing the agreement among different LC-MS/MS methods, overcoming the lack of standardization highlighted by the Vitamin D External Quality Assessment Schemes (DEQAS) [9].

The purpose of this work is to compare two commercial kits for $25-\mathrm{OHD}_{2} / \mathrm{D}_{3}$ determination by LC-MS/MS with our entry level triple quadrupole instrument.

\section{Materials and Methods}

Serum samples were obtained from 70 subjects belonging to the hospital staff (40 males, 30 females; 18-60 age range) and submitted to periodical clinical control. All subjects have given their informed consent. Samples were collected and stored at $-80^{\circ} \mathrm{C}$. When thawed, all samples were analyzed for $25-\mathrm{OHD}_{2} / \mathrm{D}_{3}$ by LC-MS/MS with both Chromsystems (Chromsystems Instruments \& Chemicals $\mathrm{GmbH}$, Munchen, Germany) and PerkinElmer (Wallac Oy, Turku, Finland) kits.

Water, acetonitrile, and formic acid (LC-MS grade) were purchased from Baker (Mallinckrodt Baker Italy, Milan, Italy).

Analyses were performed using a triple stage quadrupole TSQ Quantum Access (Thermo Fisher, Palo Alto, CA, USA) equipped with APCI source for Chromsystems and for PerkinElmer in nonderivatized mode and with ESI source for PerkinElmer in derivatized mode.

2.1. Chromsystems Assay. In the Chromsystems kit, the preanalytical phase is simplified to only a protein precipitation, because an online trap column concentrates the analytes and separates interfering substances. The trap column is connected to an HPLC column which provides further purification.

Calibration was performed using a lyophilized multilevel serum calibrator set NIST traceable $(n=6)$ of known concentration. Low and high concentration lyophilized sera samples were used as quality controls. ${ }^{2} \mathrm{H}_{6}-25(\mathrm{OH}) \mathrm{D}_{3}$ was used as internal standard (IS) to correct for sample treatment and instrument variability.

Samples, calibrators, and quality controls were prepared according to the manufacturer's instructions. Briefly, to $100 \mu \mathrm{L}$ of serum sample, $25 \mu \mathrm{L}$ of precipitation reagent and $200 \mu \mathrm{L}$ of internal standard were added. After an incubation of 10 minutes, samples were centrifuged at $15000 \times \mathrm{g}$ for 5 minutes, and $200 \mu \mathrm{L}$ was transferred into the vials. $50 \mu \mathrm{L}$ was injected into the HPLC-MS/MS system.

Samples were analyzed using an APCI source to maximize sensitivity. The APCI source was working in the positive mode, producing positively charged ions in the form of $\left[\mathrm{H}^{+}\right]$adduct ions. Discharge current was maintained at $7.0 \mu \mathrm{A}$; vaporizer temperature was maintained at $400^{\circ} \mathrm{C}$ with a capillary temperature of $300^{\circ} \mathrm{C}$. Gas settings were sheath gas pressure, 40 (arbitrary units); auxiliary gas pressure, 35 (arbitrary units); ion sweep gas pressure, 0 (arbitrary units). Argon was used as collision gas at a collision pressure of 1.5 mTorr.
TABLE 1: Compounds dependent MS/MS parameters for Chromsystems (a) and for PerkinElmer (b) assays.

(a)

\begin{tabular}{lccc}
\hline & \multicolumn{2}{c}{ Chromsystems } & \\
Compound & SRM & $\begin{array}{c}\text { Collision } \\
\text { Energy }[\mathrm{eV}]\end{array}$ & $\begin{array}{c}\text { Tube Lens } \\
{[\mathrm{V}]}\end{array}$ \\
\hline $25(\mathrm{OH}) \mathrm{D}_{3}$ & $383.2 \rightarrow 210.8$ & 23 & 80 \\
$25(\mathrm{OH}) \mathrm{D}_{2}$ & $395.2 \rightarrow 268.8$ & 17 & 80 \\
$25(\mathrm{OH}) \mathrm{D}_{3} / \mathrm{D}_{2}$ IS & $389.3 \rightarrow 210.8$ & 28 & 80 \\
\hline
\end{tabular}

(b)

\begin{tabular}{lccc}
\hline \multicolumn{4}{c}{ PerkinElmer } \\
Compound & SRM & $\begin{array}{c}\text { Collision Energy } \\
{[\mathrm{eV}]}\end{array}$ & $\begin{array}{c}\text { Tube Lens } \\
{[\mathrm{V}]}\end{array}$ \\
\hline $25(\mathrm{OH}) \mathrm{D}_{3} \mathrm{Cal}$ & $613.4 \rightarrow 298.1$ & 19 & 110 \\
$25(\mathrm{OH}) \mathrm{D}_{3} \mathrm{IS}$ & $610.1 \rightarrow 310.1$ & 19 & 110 \\
$25(\mathrm{OH}) \mathrm{D}_{3}$ & $607.4 \rightarrow 298.1$ & 19 & 110 \\
$25(\mathrm{OH}) \mathrm{D}_{2} \mathrm{Cal}$ & $625.4 \rightarrow 298.1$ & 17 & 110 \\
$25(\mathrm{OH}) \mathrm{D}_{2} \mathrm{IS}$ & $622.4 \rightarrow 301.1$ & 17 & 110 \\
$25(\mathrm{OH}) \mathrm{D}_{2}$ & $619.4 \rightarrow 298.1$ & 17 & 110 \\
\hline
\end{tabular}

Mobile phases (A and B) were used independently in isocratic mode with trap column, and analytical column respectively. All materials and reagents were provided by the manufacturers. Total run time was 6.5 minutes.

The selected reaction monitoring (SRM) transitions for each analyte, their respective collision energy, and tube lens values were reported in Table 1(a).

2.2. PerkinElmer Assay. PerkinElmer kit uses a combination of solvent extraction and protein precipitation procedures. This kit can be alternatively used with derivatization, using ESI source, or without derivatization, using APCI. Derivatization improves ionization efficiency and MS/MS signal intensity of the analytes. In our preliminary tests, our entry-level mass spectrometer showed an inadequate sensitivity for quantification of serum $25(\mathrm{OH}) \mathrm{D}_{2}$ and $25(\mathrm{OH}) \mathrm{D}_{3}$ using the kit in nonderivatized mode (data not shown). Kit was then used only in derivatized mode. Calibration was performed using 7 calibrator points (charcoal stripped human serum enriched with six increasing levels of ${ }^{2} \mathrm{H}_{6}-25(\mathrm{OH}) \mathrm{D}_{2}$ and $\left.{ }^{2} \mathrm{H}_{6}-25(\mathrm{OH}) \mathrm{D}_{3}\right)$. Three control levels (lyophilized serum added with increasing amount of ${ }^{2} \mathrm{H}_{6}-25(\mathrm{OH}) \mathrm{D}_{2}$ and $\left.{ }^{2} \mathrm{H}_{6}-25(\mathrm{OH}) \mathrm{D}_{3}\right)$ were used as quality controls.

For each analyte specific isotopically labeled internal standards $\left({ }^{2} \mathrm{H}_{3}-25(\mathrm{OH}) \mathrm{D}_{2}\right.$ for $\mathrm{VitD}_{2}$ and ${ }^{2} \mathrm{H}_{3}-25(\mathrm{OH}) \mathrm{D}_{3}$ for $\mathrm{VitD}_{3}$ ) were used.

Samples, calibrators, and quality controls were prepared according to the manufacturer's instructions with slightly modifications in order to enhance sensitivity. Briefly, to $150 \mu \mathrm{L}$ of serum sample, $300 \mu \mathrm{L}$ of daily precipitation solution (DPS, IS solution in acetonitrile $0.1 \%$ formic acid) was added. After an incubation of 10 minutes samples were centrifuged at $15000 \times \mathrm{g}$ for 5 minutes, and $300 \mu \mathrm{L}$ was transferred into 
96 well plates. Samples were placed under a stream of high purity dry nitrogen gas until all the samples were dry. $50 \mu \mathrm{L}$ of derivatization reagent was added to each wel,l and the plate, covered with aluminum foil, was shaken at $750 \mathrm{rpm}$ for 10 minutes. After removing the aluminum foil $50 \mu \mathrm{L}$ of quench solution was added to each well, and the plate, covered with aluminum foil, was shaken at $750 \mathrm{rpm}$ for 10 minutes. The plate was loaded onto the autosampler, and $50 \mu \mathrm{L}$ were injected into the HPLC-MS/MS system.

For derivatizated assay, among the columns proposed, we selected a Waters XBridge C8 $(3.5 \mu \mathrm{m} 2.1 \times 100 \mathrm{~mm})$ equilibrated with a gradient of water/methanol added with $0.1 \%$ formic acid and $0.025 \%$ additive (provided by the manufacturer). While, for nonderivatized assay, we used a C18 Beta Basic $5 \mu \mathrm{m} 2.1 \times 100 \mathrm{~mm}$ column equilibrated with a different gradient of water/methanol added with $0.1 \%$ formic acid. Total run time was 9.0 and 6.0 minutes for derivatized and underivatized assays, respectively.

In derivatized assay, the ESI source was working in the positive mode, producing positively charged ions in the form of $\left[\mathrm{H}^{+}\right]$adduct ions. Capillary voltage was maintained at $3800 \mathrm{~V}$, with a capillary temperature of $300^{\circ} \mathrm{C}$. Gas settings were sheath gas pressure, 40 (arbitrary units); auxiliary gas pressure, 5 (arbitrary units); ion sweep gas pressure, 0 (arbitrary units). Argon was used as collision gas at a collision pressure of 1.5 mTorr.

The MRM transitions for each analyte, their respective collision energy, and tube lens values were reported in Table 1(b).

In non-derivatizated assay, the APCI source was working in positive mode, producing positively charged ions in the form of $\left[\mathrm{H}^{+}\right]$adduct ions. Discharge current was maintained at $7.0 \mu \mathrm{A}$; vaporizer temperature was maintained at $430^{\circ} \mathrm{C}$ with a capillary temperature of $300^{\circ} \mathrm{C}$. Gas settings were sheath gas pressure, 40 (arbitrary units); auxiliary gas pressure, 5 (arbitrary units); ion sweep gas pressure, 0 (arbitrary units). Argon was used as collision gas at a collision pressure of 1.5 mTorr.

2.3. Methods Evaluation. The following parameters were assessed: linearity, limit of quantification (LOQ), limit of detection (LOD), and imprecision.

LOD and LOQ were evaluated by measuring the lower calibration point serially diluted with water.

The imprecision was evaluated using all the quality controls (QCs), three for PerkinElmer and two for Chromsystems. To evaluate within-assay imprecision, each QC was measured ten times in the same analytical run; betweenassay imprecision was evaluated by measuring in duplicate the same QC samples for ten consecutive days.

$25-\mathrm{OHD}_{3}$ values obtained by the LC-MS/MS methods were correlated using linear regression analysis. The bias of results was analyzed according to Bland-Altman [10].

Data acquisition was carried out using the mass spectrometer software (Excalibur 2.0.7, Thermo Fisher, Palo Alto, CA, USA). Quantitative analyses were carried out using Excalibur software for the Chromsystems method and Microsoft Excel 2010 (Microsoft Office 2010) for the
PerkinElmer method. Statistical analysis was performed using Microsoft Excel 2010 (Microsoft Office 2010).

\section{Results}

Figure 1(a) shows, from top to bottom, typical SRM chromatograms of $25-\mathrm{OHD}_{3}$, IS $\left({ }^{2} \mathrm{H}_{6}-25(\mathrm{OH}) \mathrm{D}_{3}\right)$, and $25-\mathrm{OHD}_{2}$ obtained using the Chromsystems kit. The retention time of these analytes is approximately $2.8 \mathrm{~min}$.

Figure 1(b) shows, from top to bottom, typical SRM chromatogram of $25-\mathrm{OHD}_{3}$, IS ${ }^{2} \mathrm{H}_{3}-25(\mathrm{OH}) \mathrm{D}_{3}, 25-\mathrm{OHD}_{2}$ and IS ${ }^{2} \mathrm{H}_{3}-25(\mathrm{OH}) \mathrm{D}_{2}$ obtained using the PerkinElmer kit. The retention time is approximately $4.0 \mathrm{~min}$.

In derivatized assay option, chemical modification of the $25-\mathrm{OHD}_{2}$ and $25-\mathrm{OHD}_{3}$ is achieved by derivatizing them in the extracted serum using 4-Phenyl-1,2,4-triazoline-3,5dione (PTAD). In this reaction, PTAD is selectively added to the cis-diene double bonds of the $25-\mathrm{OHD}_{2} / \mathrm{D}_{3}$ molecules, resulting in the generation of a new chiral center and the subsequent formation of a new pair of $25-\mathrm{OHD}_{2} / \mathrm{D}_{3}$ diastereoisomers. Although partially resolved both $6 \mathrm{~S}$ - and 6R-isomers signals should be finally combined for quantitative determination of $25-\mathrm{OHD}_{2}$ and $25-\mathrm{OHD}_{3}$ in the samples. This could explain the poor peak shape showed in Figure 1(b).

Both chromatographic runs are without interferences, confirming the high selectivity of these methods.

Performance characteristics are acceptable for both methods. According to manufacturer's instructions the linearity of the PerkinElmer assay is $329 \mathrm{ng} / \mathrm{mL}$ for $25-\mathrm{OHD}_{2}$ and $314 \mathrm{ng} / \mathrm{mL}$ for $25-\mathrm{OHD}_{3}$, and the linearity of the Chromsystems assay is $250 \mathrm{ng} / \mathrm{mL}$ for both $25-\mathrm{OHD}_{2}$ and $25-\mathrm{OHD}_{3}$.

LOQ, estimated as the lowest concentration of $25-\mathrm{OHD}_{3}$ where the relative uncertainty of a single measurement is reproducible within $\pm 20 \%$, was $3.0 \mathrm{ng} / \mathrm{mL}$ for PerkinElmer kit and $4.1 \mathrm{ng} / \mathrm{mL}$ for Chromsystems kit.

LOD, defined as the minimum concentration of 25$\mathrm{OHD}_{3}$ which gives a signal three times higher than the noise, was $1.6 \mathrm{ng} / \mathrm{mL}$ for PerkinElmer kit and $2.6 \mathrm{ng} / \mathrm{mL}$ for Chromsystems kit.

LOQ for $25-\mathrm{OHD}_{2}$ was $1.4 \mathrm{ng} / \mathrm{mL}$ for PerkinElmer kit and 3.0 for Chromsystems kit; the LOD of $25-\mathrm{OHD}_{2}$ was $0.5 \mathrm{ng} / \mathrm{mL}$ for PerkinElmer kit and $2.3 \mathrm{ng} / \mathrm{mL}$ for Chromsystems kit. Since $25-\mathrm{OHD}_{2}$ is normally present in very low concentrations (lower than $2.0 \mathrm{ng} / \mathrm{mL}$ ), its determination is not possible with our entry level instrument using Chromsystems kit. Moreover, also using a slightly more performing instrument, as reported in the package insert of the Chromsystems kit, LOQ $(2.4 \mathrm{ng} / \mathrm{mL})$ is not adequate for the quantification of 25-OHD.

Intra-assay imprecision for $25-\mathrm{OHD}_{3}$ ranged from $3.6 \%$ to $3.7 \%$ for Chromsystems and from $4.6 \%$ to $4.9 \%$ for PerkinElmer. Interassay imprecision for $25-\mathrm{OHD}_{3}$ ranged from $4.6 \%$ to $4.8 \%$ for Chromsystems and from $4.2 \%$ to $5.1 \%$ for PerkinElmer.

Intra-assay imprecision for $25-\mathrm{OHD}_{2}$ ranged from $3.8 \%$ to $4.0 \%$ for Chromsystems and from $4.5 \%$ to $4.8 \%$ for PerkinElmer. Interassay imprecision for $25-\mathrm{OHD}_{2}$ ranged 

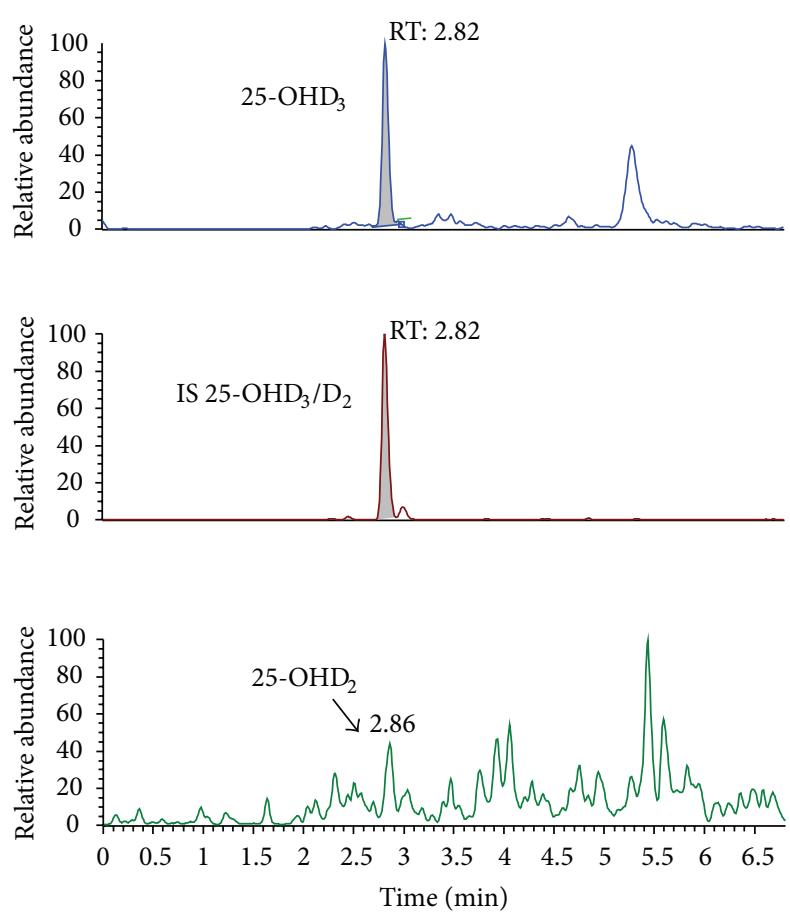

(a)
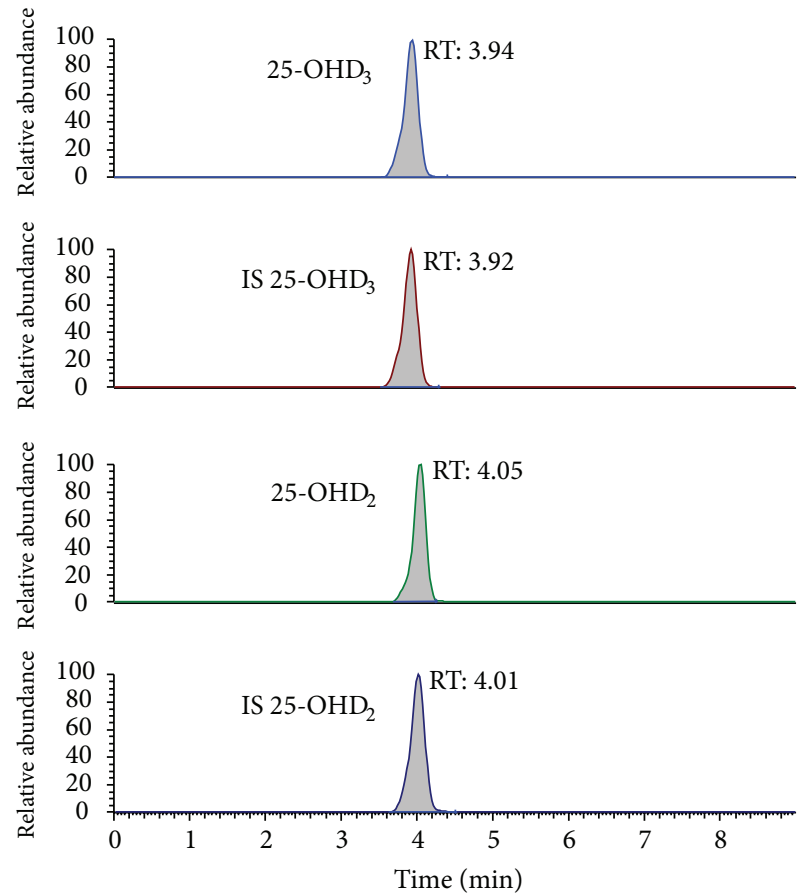

(b)

Figure 1: Typical SRM chromatograms of a serum sample $\left(23.4 \mathrm{ng} / \mathrm{mL} 25-\mathrm{OHD}_{3}\right.$ and $25-\mathrm{OHD}_{2}$ not detectable) assayed using the Chromsystems kit. The retention time of $25-\mathrm{OHD}_{2} / \mathrm{D}_{3}$ is 2.8 minutes (a). Typical SRM chromatogram of a serum sample (21.8 ng/mL $25-$ $\mathrm{OHD}_{3}$ and $25-\mathrm{OHD}_{2} 1.6 \mathrm{ng} / \mathrm{mL}$ ) assayed using the PerkinElmer kit. The retention time is $4.0 \mathrm{~min}(\mathrm{~b})$.

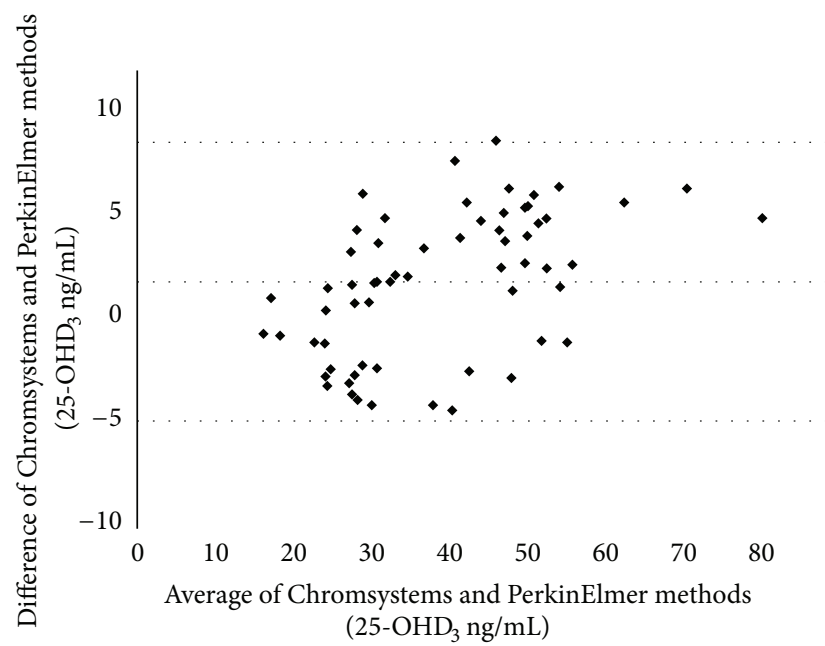

FIGURE 2: Bland-Altman plots of the differences between 25- $\mathrm{OHD}_{3}$ values obtained by Chromsystems and PerkinElmer kits. Mean \pm 1.96 SD.

from $5.7 \%$ to $6.6 \%$ for Chromsystems and from $4.3 \%$ to $5.1 \%$ for PerkinElmer.

Figure 2 shows the Bland-Altman plots of the differences between $25-\mathrm{OHD}_{3}$ values obtained with Chromsystems and PerkinElmer methods. Mean bias was $1.9 \mathrm{ng} / \mathrm{mL}$, showing a good agreement between the two methods, confirmed by linear regression analysis $\left(R^{2}: 0.94 ; Y_{\text {Chromsystems }}=\right.$ $\left.1.15 X_{\text {PerkinElmer }}-8.44\right)$.

\section{Conclusion}

Using the Chromsystems kit, manual sample preparation is minimized and limited to a simple and effective protein precipitation.

The PerkinElmer kit without derivatization does not guarantee acceptable performance with our LC-MS/MS system, but the manufacturer reports better analytical performance using a more performant instrument. Derivatization is more time consuming but provides sufficient sensitivity for the detection of $25-\mathrm{OHD}_{2}$.

Chromsystems kit does not declare neither the type of the column nor the composition of mobile phases, while PerkinElmer does.

In PerkinElmer kit, automated calculation is made highly complicated by the presence of different deuterated standards and cannot be performed by our software.

Several studies indicate the presence of $25-\mathrm{OHD}_{2} / \mathrm{D}_{3}$ epimers, particularly 3 epi- $25 \mathrm{OH}-\mathrm{D}_{2}$ and 3 epi- $25 \mathrm{OH}-\mathrm{D}_{3}$, like potential confounders in $25-\mathrm{OHD}_{2} / \mathrm{D}_{3}$ measurements. The presence of these epimers was initially considered relevant only for children younger than one year [11], but recently work showed that the concentration of $25-\mathrm{OHD}_{2} / \mathrm{D}_{3}$ epimers may also be significant in adults [12]. 
For these reasons, both PerkinElmer and Chromsystems provide an alternative kit that permits to discriminate and quantify $25-\mathrm{OHD}_{2} / \mathrm{D}_{3}$ epimers.

Therefore as a future perspective, we intend to clarify the possible role of epimers in adults using LC-MS/MS methods able to separate the less biologically active $25-\mathrm{OHD}_{2} / \mathrm{D}_{3}$ epimers.

\section{References}

[1] M. F. Holick, "Vitamin D deficiency," The New England Journal of Medicine, vol. 357, pp. 266-281, 2007.

[2] K. M. Seamans and K. D. Cashman, "Existing and potentially novel functional markers of VitD status: a systematic review," The American Journal of Clinical Nutrition, vol. 89, pp. 1997S2008S, 2009.

[3] D. B. Endres and R. K. Rude, "Bone and mineral metabolism," in Tietz Textbook of Clinical Chemistry and Molecular Diagnostics, C. A. Burtis, E. A. Ashwood, and D. E. Bruns, Eds., Elsevier Saunders, St. Louis, Mo, USA, 4th edition, 2006.

[4] M. F. Holick, "Vitamin D status: measurement, interpretation, and clinical application," Annals of Epidemiology, vol. 19, no. 2, pp. 73-78, 2009.

[5] A. M. Wallace, S. Gibson, A. de la Hunty, C. LambergAllardt, and M. Ashwell, "Measurement of 25-hydroxyvitamin $\mathrm{D}$ in the clinical laboratory: Current procedures, performance characteristics and limitations," Steroids, vol. 75, no. 7, pp. 477$488,2010$.

[6] H. W. Moon, J. H. Cho, M. Hur, J. Song et al., "Comparison of four current 25-hydroxyvitamin D assays," Clinical Biochemistry, vol. 45, pp. 326-330, 2012.

[7] S. S. C. Tai, M. Bedner, and K. W. Phinney, "Development of a candidate reference measurement procedure for the determination of 25-hydroxyvitamin $\mathrm{D}_{3}$ and 25-hydroxyvitamin $\mathrm{D}_{2}$ in human serum using isotope-dilution liquid chromatography tandem mass spectrometry," Analytical Chemistry, vol. 82, no. 5, pp. 1942-1948, 2010.

[8] H. C. M. Stepman, A. Vanderroost, K. Van Uytfanghe, and L. M. Thienpont, "Candidate reference measurement procedures for serum 25-hydroxyvitamin $\mathrm{D}_{3}$ and 25-hydroxyvitamin $\mathrm{D}_{2}$ by using isotope-dilution liquid chromatography-tandem mass spectrometry," Clinical Chemistry, vol. 57, no. 3, pp. 441-448, 2011.

[9] C. J. Farrell, S. Martin, B. McWhinney, I. Straub, P. Williams, and M. Herrmann, "State-of-the-art vitamin D assays: a comparison of automated immunoassays with liquid chromatographytandem mass spectrometry methods," Clinical Chemistry, vol. 58, pp. 531-542, 2012.

[10] J. M. Bland and D. G. Altman, "Comparing methods of measurement: why plotting difference against standard method is misleading," The Lancet, vol. 346, no. 8982, pp. 1085-1087, 1995.

[11] R. J. Singh, R. L. Taylor, G. S. Reddy, and S. K. G. Grebe, "C-3 epimers can account for a significant proportion of total circulating 25-hydroxyvitamin D in infants, complicating accurate measurement and interpretation of vitamin D status," Journal of Clinical Endocrinology and Metabolism, vol. 91, no. 8, pp. 3055-3061, 2006.

[12] G. Lensmeyer, M. Poquette, D. Wiebe, and N. Binkley, "The C3 epimer of 25 -hydroxyvitamin $\mathrm{D}_{3}$ is present in adult serum," The Journal of Clinical Endocrinology \& Metabolism, vol. 97, pp. 163-168, 2012. 

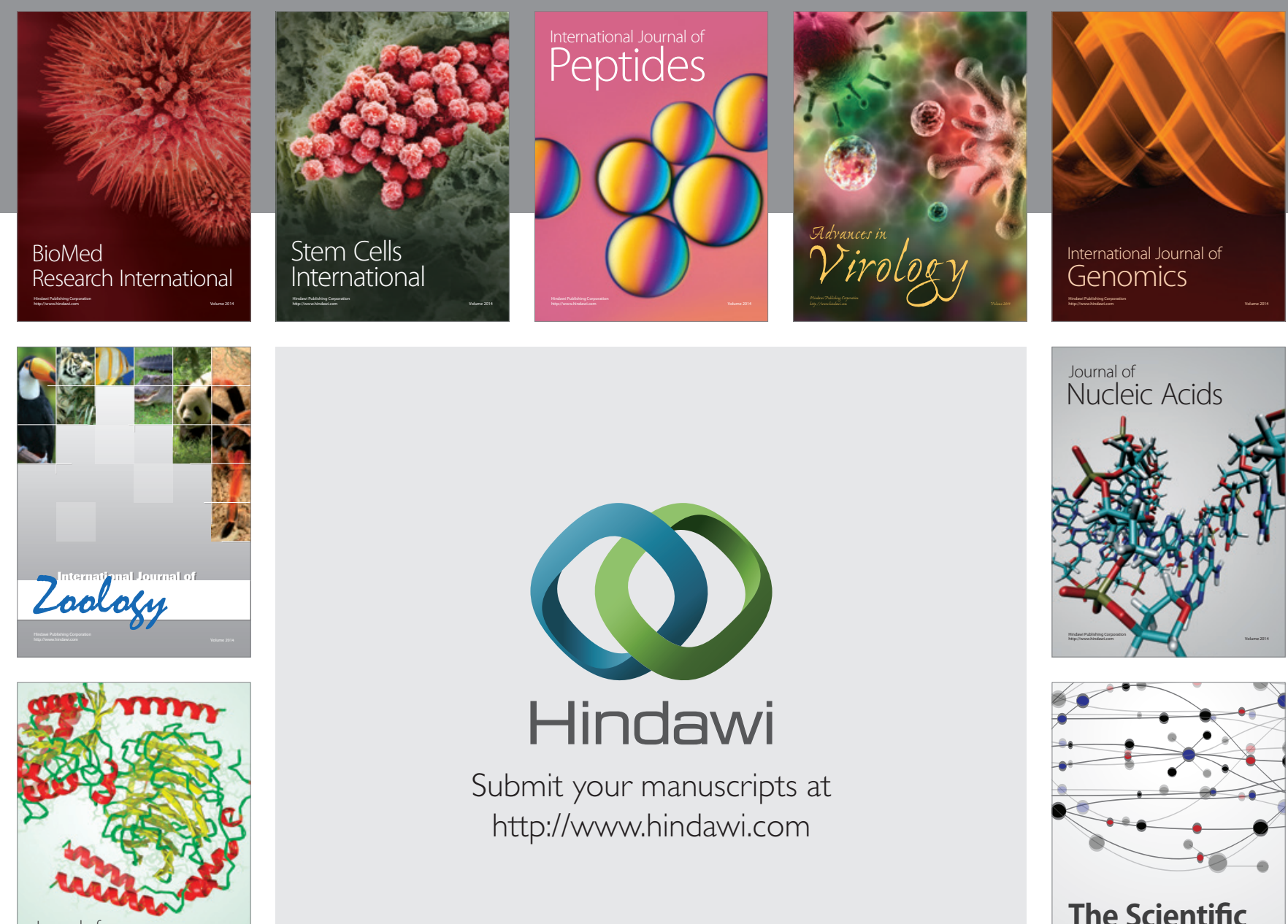

Submit your manuscripts at

http://www.hindawi.com

Journal of
Signal Transduction
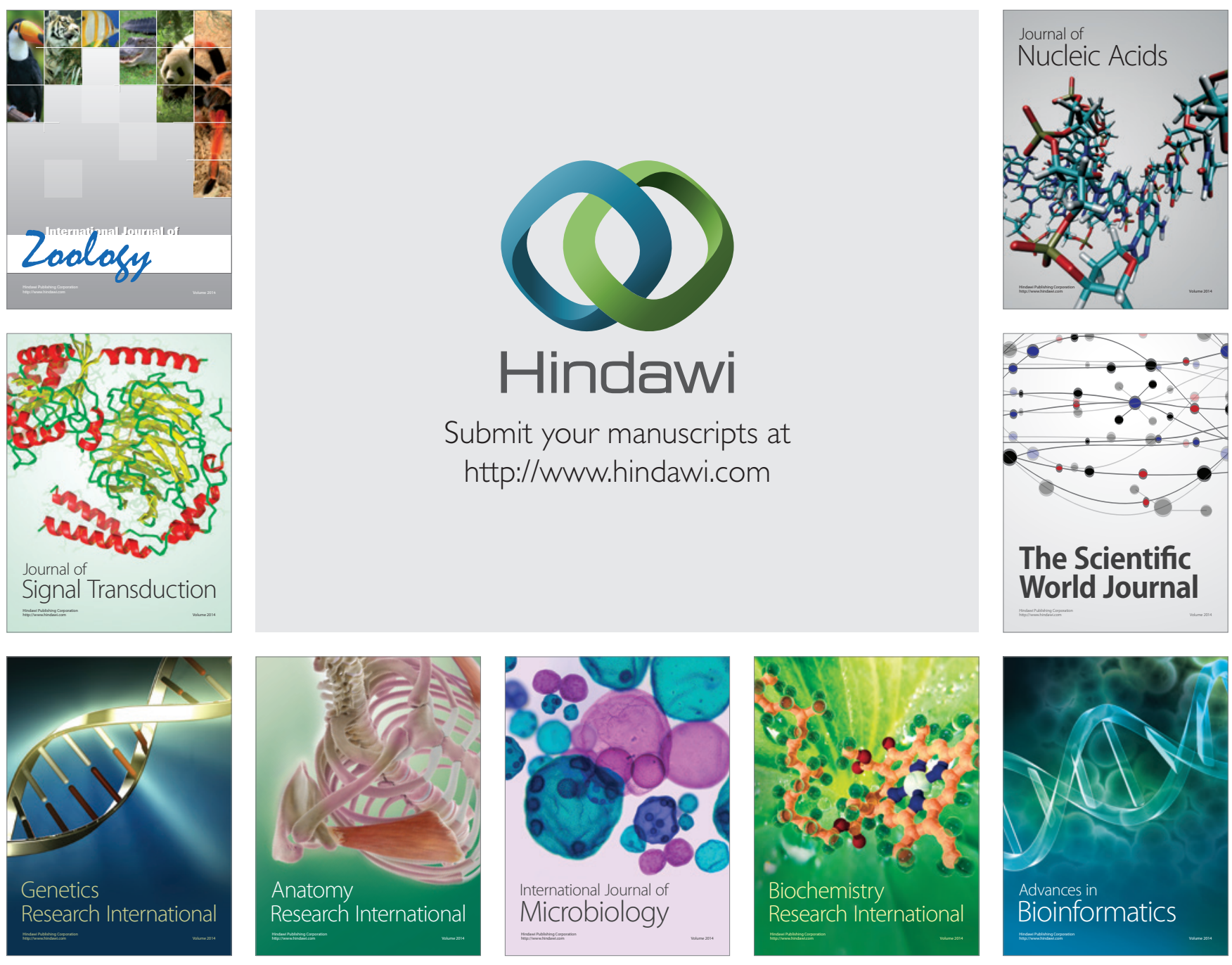

The Scientific World Journal
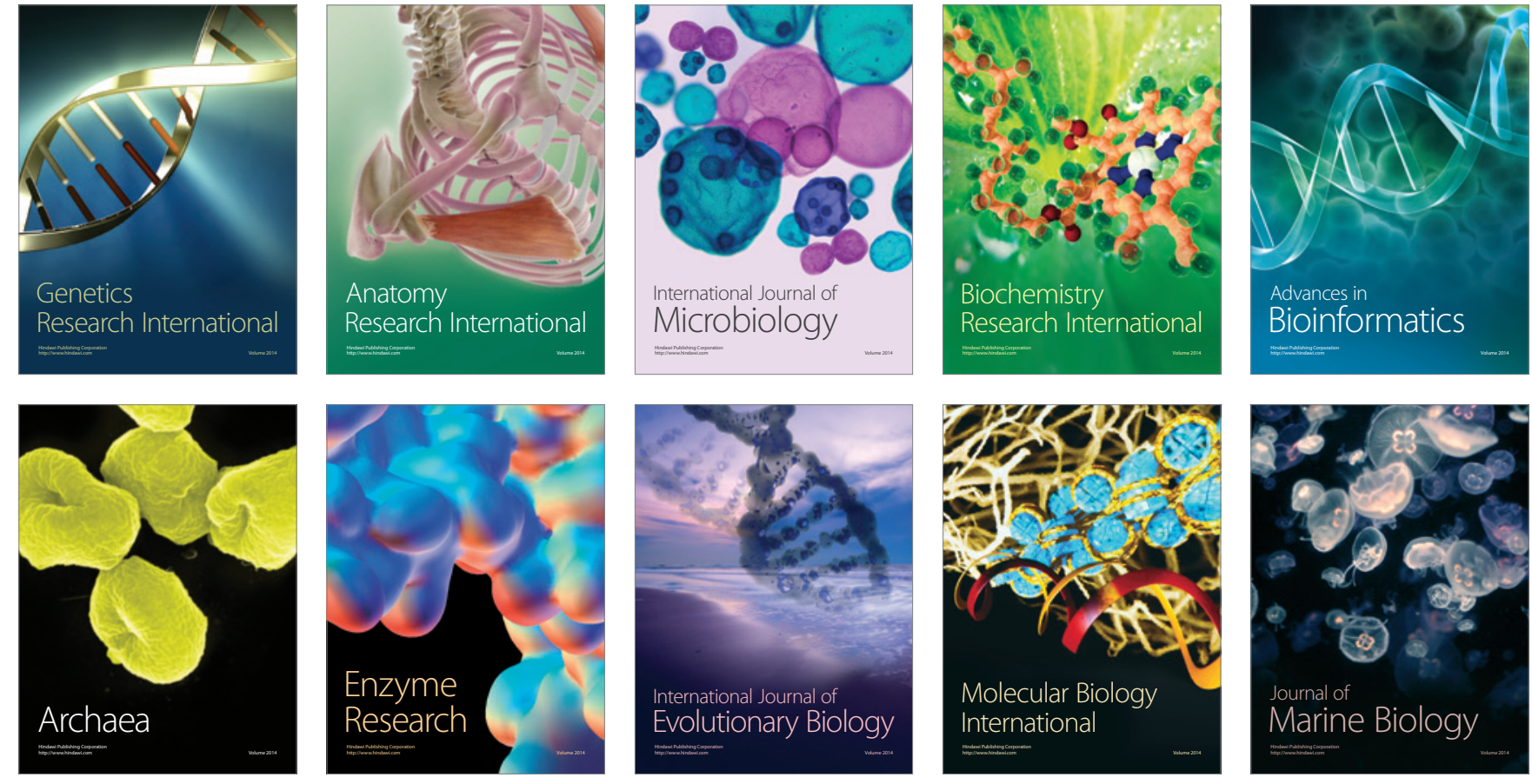